\title{
O ensino de Filosofia no Cepae
}

\author{
Evandson Paiva Ferreira*
}

\section{Resumo}

O presente artigo apresenta as reflexões que envolvem o novo projeto de Filosofia para o Cepae, o que inclui o ensino dessa disciplina no ensino médio, como também na $2^{\text {a }}$ fase do ensino fundamental ( $7^{\mathrm{a}}$ e $8^{\mathrm{a}}$ séries). Ao longo do texto, expõem-se as razões que fundamentam filosófica e pedagogicamente a relevância dessa disciplina dentro do projeto de formação proposto pelo Cepae.

Palavras-Chaves: educação básica, ensino, filosofia.

The teaching of Philosophy in Cepae

\section{Abstract}

The main goal of this article is to present some reflections on the new philosophy project for Cepae, which includes the teaching of this subject in high school as well as in the seventh and eighth grades. Throughout this text we show the philosophical and pedagogical relevance of this subject within the formation project proposed by Cepae.

KeY wORDS: elementary and high school, philosophy, teaching.

\section{APRESENTAÇÃo}

Neste artigo, faz-se uma reflexão sobre a natureza e o sentido da filosofia na sociedade, em especial na sociedade brasileira, caracterizada por uma desigualdade cruel, que nega à maioria de sua população o direito ao pensamento crítico. Refere-se ao ser que é capaz de interrogar as idéias e valores que constituem a experiência imediata do cotidiano, fazendo da cidadania uma nomenclatura sem conteúdo. Define-se, assim, o para quê da filosofia, na sociedade, o que implica voltar o olhar para a escola, pois é nela que se vê um lugar privilegiado para a problematização da realidade.

Questões históricas e de legislação, que têm permeado o ensino e a discussão sobre o ensino de filosofia, não são o objeto principal deste texto, mas estão presentes no horizonte da reflexão, dando margem para,

\footnotetext{
* Professor de Filosofia no Cepae/UFG. E-mail: evandsonpaiva@ibest.com.br
} 
em alguns momentos, fazer memória dos caminhos trilhados pela filosofia até o presente momento.

Apresentam-se os eixos que compõem esse projeto de ensino em Filosofia para a Educação Básica, compreendendo-o dentro uma proposta de formação desenvolvida pelo Centro de Ensino e Pesquisa Aplicada à Educação da Universidade Federal de Goiás (Cepae/UFG), voltada para o ensino fundamental e médio, conforme os Parâmetros Curriculares Nacionais (PCNs).

\section{FUNDAMENTAÇÃO TEÓRICO-METODOLÓGICA}

Para a compreensão da importância da Filosofia como disciplina da educação básica, deve-se refletir a respeito do sentido e da gênese desse saber, bem como de sua relevância na construção de uma sociedade comprometida com a verdade da razão crítica. Vale dizer, ao contrário da razão instrumental, que está a serviço da exploração e dominação, a razão crítica procura pensar as contradições e os conflitos sociais e políticos com intenção emancipadora, pois está comprometida também com a justiça, com a autonomia e a liberdade de pensamento e ação.

A filosofia é um saber que surge na Grécia Antiga no século VI a.C., num momento de crise de civilização, quando a cultura tradicional não garantia mais ao homem grego a coesão interna daquela sociedade. Não mais consolados pelos mitos e seus deuses, os gregos vão buscar na imanência da razão a justificação para sua existência e na história a possibilidade de um futuro razoável. Substituir a matriz simbólica mítica pela razão pôs nas mãos dos homens a responsabilidade de refletir e dar um sentido lógico à existência coletiva.

$\mathrm{Na}$ obra de Platão, encontra-se uma metáfora, a conhecida Alegoria da Caverna, que ajuda na compreensão do topos (lugar) da filosofia. Como uma pedagogia da razão, ou ainda uma pedagogia do olhar, ela ensina àqueles que a praticam a ter uma visão penetrante, sem se deixar levar pelas aparências. Nessa metáfora, a alegoria é a imagem usada por Platão para auxiliar seus interlocutores a representar o processo educativo, que tem como telos (finalidade) a educação do olhar. Fala de homens que vivem, desde pequenos, numa morada subterrânea, no fundo de uma caverna que possui apenas uma única entrada com vista para a luz em toda a sua largura. Estão presos com correntes no pescoço e nas pernas, de modo que só conseguem ver o fundo dela. Por trás desses homens, brilha um fogo no alto, e sua 
realidade se resume às sombras produzidas por essa chama, de homens que carregam objetos e conversam entre si. Estes são mais baixos que os muros, mas os objetos que ultrapassam a altura do muro, ao serem carregados, projetam suas sombras no fundo da caverna. Para os homens acorrentados, trata-se de sombras que representam a realidade dos objetos, e vão além. As vozes dos carregadores são, assim, entendidas como vozes das sombras dos objetos, de modo que aquilo que parece ser o real não passa de ilusão.

Platão, convidado à reflexão, propõe a seus interlocutores imaginar o que aconteceria se um daqueles homens fosse libertado de tal condição e forçado a girar o olhar para a luz e responde que "[...] não apenas tudo isso lhe causaria dor, como também o deslumbramento o impediria de ver os objetos cujas sombras até então ele enxergava” (Platão, 2000, VII, 515d). Um interlocutor, então, lhe mostraria os objetos dos quais via apenas as sombras, sendo levado a sair da caverna, a subir o caminho árduo que leva para fora. Assim, os olhos desse homem, que já estavam feridos pela luz do fogo dentro da caverna, sofreriam ainda mais lá fora, em contato com a luz do sol, até se acostumar com ela e então poder enxergar diretamente cada coisa, o que levaria tempo.

Platão continua a perguntar: e se ele voltasse para o fundo da caverna? Desse modo, faz ver o conflito e a incompreensão do senso comum diante do homem da razão. Talvez esse homem fosse até morto, pois sua presença causaria um mal-estar, uma vertigem naqueles que não podiam ou não queriam ver outras realidades.

A força educativa da Filosofia é o ensinar a perguntar e a responder com o rigor do exercício da razão crítica. É pela reflexão que o homem pode superar o senso comum e seus mitos. Não se deve ter receio dessa conversão do olhar, um olhar que penetra e intervém na realidade.

Diante da sociedade do não-pensamento, tão desacostumada a se questionar, a se perguntar pelo sentido das coisas, a filosofia, considerada a mais "inútil" das disciplinas e saberes, se propõe a pensar o útil e o inútil, ajudando essa mesma sociedade a romper com os seus preconceitos. Chaui (2003, p. 24) é quem talvez tenha dado a melhor justificativa para a utilidade da Filosofia, ao redefinir o que é útil e inútil:

Se abandonar a ingenuidade e os preconceitos do senso comum for útil; se não se deixar guiar pela submissão às idéias dominantes e aos poderes estabelecidos for útil; se buscar compreender a significação do mundo, da cultura, da história for útil; se conhecer o sentido das criações humanas nas 
artes, nas ciências e na política for útil, se dar a cada um de nós e à nossa sociedade os meios para serem conscientes de suas ações numa prática que deseja a liberdade e a felicidade para todos for útil, então poderemos dizer que a filosofia é o mais útil de todos os saberes de que os seres humanos são capazes.

Ao ser inserida no currículo do Cepae, a Filosofia não se coloca como portadora de um saber superior deslocado da proposta filosóficopedagógica da escola, mas como um saber que justifica sua presença nesse projeto, na medida em que ajuda na formação dos níveis médio e fundamental. Vale assinalar, desenvolve no educando a curiosidade intelectual, o senso e a capacidade de buscar o conhecer.

Mais que trabalhar conteúdos específicos de Filosofia, o compromisso maior da disciplina é formar uma atitude filosófica diante da vida. Ela contribui, assim, para que os educandos tomem uma distância crítica do cotidiano e de si mesmos, para que sejam capazes de problematizar, de levantar questões, de interrogar as crenças, o não-pensado, o não-falado, o não-visto, enfim, formando os educandos no cultivo da admiração, do espanto e do amor à sabedoria.

\section{FiLOSOFIA NA EDUCAÇĀo BÁSICA ESCOLAR BRASILEIRA}

A Filosofia chega ao Brasil com os padres jesuítas, em 1549, que tinham uma dupla missão de apoio ao processo colonizador: catequizar os índios e cuidar da educação dos filhos da elite da colônia. Trouxeram na bagagem a ratio studiorum, programa pedagógico carregado de retórica e erudição, com preocupaçōes herdadas da Filosofia Medieval e sua intrínseca relação com o ethos religioso.

Segundo Silvestre (s/d), desde o período colonial, a presença ou não da filosofia no nível médio sempre esteve condicionada ao momento histórico e às transformações econômicas ocorridas no Brasil. Após o golpe de Estado, em 1964, e a reforma do Estado brasileiro, novamente a filosofia tem o seu lugar redefinido. Três anos antes do golpe, a LDB de 1961 havia garantido a Filosofia como disciplina no nível médio. Em 1971, uma nova Lei de Diretrizes e Bases direciona a educação escolar brasileira, num sentido que ainda não se conseguiu desviar, cuja principal característica é a desvalorização das humanidades. 
Com a inclusão das disciplinas Organização Social e Política do Brasil e Educação Moral e Cívica, que continham noções de direito, sociologia e política, a Filosofia se torna facultativa, nunca sendo assumida pelas escolas, devido à grande quantidade de disciplinas obrigatórias e ao fato de não "cair no vestibular". Apesar de não ter sido excluída oficialmente da escola, ela vai sendo esquecida lentamente.

Ainda na década de 1970, começam a surgir movimentos que almejavam o retorno da Filosofia no nível médio. Em 1976, por exemplo, foi fundada a Sociedade de Estudos e Atividades Filosóficos - Seaf -, que congregava professores e estudantes de filosofia e organizou, nas esferas regional e nacional, encontros, simpósios e ciclos de conferências de filosofia (Cadernos Seaf, 1978).

No estado de São Paulo, algumas poucas escolas públicas e particulares mantiveram a disciplina em seus currículos. Em Goiás, nos Colégios Lyceu de Goiânia e Universitário (Colu), da rede estadual, ela era desenvolvida com conteúdos de Psicologia. No Instituto de Educação de Goiás (IEG), ministrava-se Filosofia da Educação no curso Magistério.

Com a nova LDB - Lei no 9.394, de 20 de dezembro 1996 -, a discussão sobre o ensino de Filosofia no ensino médio ganha novos contornos, ao enfatizar o conceito de cidadania e preocupar-se com uma formação voltada para o seu exercício, embora não os explicitasse. De acordo com o art. $36 \$ 1^{\circ}$, o educando deve demonstrar "domínio dos conhecimentos de Filosofia e de Sociologia [...]". Presente na nova legislação, a Filosofia, agora acompanhada da Sociologia, começa a reconquistar seu status de disciplina, apesar de ainda constarem como optativas.

Em Goiás, o último concurso público para seleção de professores da rede estadual, realizado em dezembro de 2003, incluiu vagas para professores de Filosofia. Vale destacar que, desde o final da década de 1990, esse estado vem implantando tal disciplina no ensino médio. Para completar a carga horária mínima, os professores aprovados davam aula de várias outras disciplinas, o que obrigou a Secretaria de Educação a tomar medidas para impedir isso. Desse modo, como uma carga horária de horas/aula no ensino médio, essa disciplina levou os professores a dar aulas em muitas turmas e em mais de uma escola. Atualmente, o ensino de Filosofia é obrigatório nas escolas estaduais de Goiás, ficando a critério de cada uma delas incluir ou não na sua matriz curricular. 


\section{Filosofia no Cepae}

O Cepae faz parte dessa história da Filosofia no ensino médio. Uma história que começa em 1982, quando ainda era apenas o Colégio de Aplicação. Para entender essa mudança na nomenclatura, e também na natureza da instituição dentro da UFG, faz-se um breve memorial.

O Colégio de Aplicação foi criado em 12 de março de 1966, pelo Decreto Lei no 9.053, e começou a funcionar em março de 1968, no Prédio da Faculdade de Educação, órgão ao qual era ligado, constituindo-se em laboratório para novas experiências pedagógicas das licenciaturas da UFG. A partir de 1980, o Colégio de Aplicação começa a sofrer algumas mudanças quanto a sua natureza dentro da universidade. A primeira delas é a reclassificação de seus professores, da carreira de $1^{\circ}$ e $2^{\circ}$ graus, para o magistério superior. Em 1982 é criado o Departamento de Estudos Aplicados e Pesquisa Aplicados à Educação (Depae), ainda vinculado à Faculdade de Educação. Em março de 1994, é criado o Cepae, com status de unidade acadêmica e desligado da Faculdade de Educação. A sua nova função é desenvolver o ensino, a pesquisa e a extensão, mediante a participação na formação de novos educadores, atendendo às licenciaturas. Desse modo, o Cepae não abandona o projeto inicial do Colégio de Aplicação, mas o amplia.

O início do ensino de Filosofia começa com a professora Maria Helena Café (da Faculdade de Educação, que no início da década de 1980 exerceu o cargo de supervisora no Colégio de Aplicação). O trabalho teve a duração de dois meses, totalizando dezesseis horas-aula, em oito encontros com dezessete alunos. A sua proposta visava uma formação de atitude filosófica do aluno diante da obra de arte. Ao pensar a arte, ele deveria pensar as circunstâncias em que essa é produzida.

Os objetivos da disciplina propunham um questionamento das circunstâncias que envolvem o homem, o diálogo com a obra de arte, a compreensão da cultura como transformação do homem e do mundo, a arte como um fazer do homem no mundo, e a compreensão do filosofar como ato concreto do sujeito situado historicamente.

Café (1983, p. 2-3) descreve a primeira experiência com Filosofia no Colégio de Aplicação:

[...] comecei por explorar um texto sobre a vivência comum das pessoas que estão no mundo, mundo que nos aparece com suas facilidades e dificuldades. As interrogações foram surgindo e, após o estudo de um texto 
de Jaspers, os alunos descobriram que o filosofar é um ato natural de uma pessoa que pensa e que sente, e verbalizam a diferença entre filosofia e filosofar. A partir daí, no $3^{\circ}$ encontro, diante de duas obras de arte: uma moderna (Magritte) e outra gótica (vitral), com slides sobre o conjunto da Catedral e das questôes - o que você sente? O que sentia o autor? - os alunos chegaram a uma conclusão surpreendente: gostaram do gótico, mas entendiam mais o moderno, porque viviam no mesmo momento histórico do autor. Esta conclusão, na $3^{a}$ aula, me fez sonhar. Prosseguimos, então, por questionar os quatro momentos da relação estética a partir do texto "O Artista, a Circunstância, a Obra de Arte, o Espectador". Finalmente utilizei o texto de Mounier para ligar o filosofar e o diálogo com a obra de arte. Como resultado final, os alunos descobriram que sabiam ver mais, que era possível dialogar com a obra de arte e identificaram a mesma circunstância - seca - no quadro "O Enterro" de Portinari e no livro Vidas Secas de Graciliano Ramos.

Com essa primeira experiência com a Filosofia, os alunos fizeram um pedido: estudar outros assuntos que fossem além dos conteúdos de caráter pragmático e os ajudassem a compreender o mundo em que viviam e a si mesmos.

Em 18 de outubro de 1982, com a promulgação da Lei no 7.044, alteraram-se dispositivos da Lei no $5.692 / 71$, referentes à profissionalização no ensino de $2^{\circ}$ grau. Os artigos $4^{\circ}$ e $5^{\circ}$ deixavam a critério das escolas a constituição do currículo pleno, "para atender, pela parte diversificada, aos planos da escola a aos alunos" (Café, 1983, p. 3). Com isso, o Colégio de Aplicação elabora um projeto experimental, que duraria seis anos, começando em 1983, de um novo $2^{\circ}$ grau.

No ano de 1983 teve início o desenvolvimento da disciplina Introdução à Filosofia, obrigatória na $1^{\text {a }}$ série do $2^{\circ}$ grau, com duas aulas por semana (cinqüenta minutos cada), em duas turmas, com 35 alunos em cada uma.

Café (1983, p. 6) descreve essa nova experiência com os alunos do Colégio de Aplicação:

A idéia central de que as circunstâncias históricas determinam mudanças no modo de pensar do homem foi objeto de reflexão constante através dos momentos: pensamento mágico, racional, experimental e contemporâneo. $\mathrm{O}$ curso se desenvolveu relacionando-se com as demais disciplinas: Português nos problemas de cultura, linguagem e estrutura dos períodos; 
História nos problemas da mágica na pré-história e do pensamento racional na Grécia; com as ciências exatas no estudo dos argumentos dedutivo e indutivo, cujos exemplos e exercícios foram retirados do conteúdo de Física, Química e Biologia. O pensamento experimental foi focalizado com o nascimento da Física moderna. O problema da ciência e de seu método foi focalizado a partir do senso comum. A programação está sendo cumprida, faltando o argumento "Modus Tollens" e a problemática das ciências humanas, que será dada dentro do momento histórico do século XX.

O ensino da Filosofia no Colégio de Aplicação nasceu, assim, a partir de um pedido dos alunos, que queriam uma educação menos técnica e mais humanizante. Passadas duas décadas, hoje, no Cepae, na esteira de uma proposta significativa de formação humana, iniciada no Colégio de Aplicação, procura-se pensar a Filosofia e sua inserção no processo de formação e de construção de uma nova escola para uma nova sociedade.

\section{ENSINO FUNDAMENTAL}

A nova LDB, no artigo 32, especifica os objetivos do ensino fundamental da educação escolar, voltados para a "formação básica do cidadão".

I - o desenvolvimento da capacidade de aprender, tendo como meios básicos o pleno domínio da leitura, da escrita e do cálculo;

II - a compreensão do ambiente natural e social, do sistema político, da tecnologia, das artes e dos valores em que se fundamenta a sociedade;

III - o desenvolvimento da capacidade de aprendizagem, tendo em vista a aquisição de conhecimentos e habilidades e a formação de atitudes e valores;

IV - o fortalecimento dos vínculos de família, dos laços de solidariedade humana e de tolerância recíproca em que se assenta a vida social.

Como disciplina, a Filosofia trabalha com tais objetivos, na medida em que problematiza os valores neles explicitados em sua inserção nas várias dimensões da vida social. Ao não propor um saber moralizante, mas ético, convida o educando a um contínuo repensar dos valores e atitudes, constitutivos do diálogo, da tolerância e do respeito mútuo, como verdadeiras dimensões da convivência humana.

$\mathrm{Na} 2^{\text {a }}$ fase do ensino fundamental, a disciplina é ministrada em duas séries: $7^{\mathrm{a}}$ e $8^{\mathrm{a}}$. O que se espera da Filosofia com jovens nesse nível de 
aprendizado? Aranha (2000, p. 127) resume um pouco daquilo que acreditamos ser o fundamental da disciplina nessa fase da formação escolar:

O que se espera das novas gerações diante do desafio do novo é a disponibilidade para a invenção e a crítica, a capacidade de selecionar e compreender as informações veiculadas pela mídia e infovias com velocidade e volume cada vez maiores, a percepção holística e interdisciplinar do conhecimento em contraposição à tradicional fragmentação das ciências nas suas diversas especializações, o discernimento para ampliar os efeitos das tecnologias e para evitar o predomínio da visão tecnocrática, a capacidade de agir com autonomia nas decisões políticas e morais. E muito mais.

Pensar a Filosofia no ensino fundamental é pensar uma prática pedagógica problematizadora, cujo princípio é a formação da atitude interrogativa da inquietação do aluno diante do já dado. O ponto de partida dessa prática é a relação do homem com o mundo, além da problematização dessa relação. Problematizar é interrogar a realidade, perguntar sobre o porquê das coisas, "ad-mirar" a realidade. Nas palavras do educador Freire (1992, p. 83):

O que importa fundamentalmente à educação, contudo, como uma autêntica situação gnosiológica, é a problematização do mundo do trabalho, das obras, dos produtos, das idéias, das convicçōes, das aspiraçōes, dos mitos, da arte, da ciência, enfim, o mundo da cultura e da história, que resultando das relações homem-mundo, condiciona os próprios homens, seus criadores.

No ensino fundamental, a Filosofia é desenvolvida sob dois eixos de reflexão. $\mathrm{Na} 7^{\mathrm{a}}$ série, trabalhará a seguinte temática: $O$ homem, a sociedade e a ética. Essa introdução ao filosofar tem a preocupação de apresentar a Filosofia ao educando como uma forma de interrogar e compreender o real, mostrando que a atitude filosófica é uma prática possível a todo aquele que pensa. A singularidade da condição humana e o modo como o homem organiza e problematiza a vida e os valores servirão de pano de fundo para a introdução de conceitos filosóficos que ganharão sentido na medida em que forem relacionados com a existência humana, nas esferas pessoal e coletiva.

$\mathrm{Na} 8^{a}$ série, a temática é: $O$ homem, o conhecimento e a política. Nessa etapa de problemas, a Filosofia permite elaborar questóes que ajudam o 
educando a pensar o conhecimento como construção social e suas implicações na vida social. A interrogação da política colabora na construção do pensamento crítico sobre o que é a política, para além de seu reducionismo político-partidário. Isso facilita a construção da cidadania, além de colaborar na reflexão sobre a formação humana de cada um, o que extrapola o sentido de uma mera escolarização.

O que une esses dois eixos temáticos e dá sentido à disciplina é a preocupação em introduzir o educando no mundo das criações culturais, ajudando-o a interrogar tudo aquilo que faz parte das criações humanas: o saber e o agir humanos, o ser, a verdade, os valores, os fins, o belo e o bem.

\section{ENSINO MÉDIO}

A nova Lei de Diretrizes e Bases da Educação Nacional (Lei no 9.394/96) cria uma nova identidade ao ensino médio, integrando-o à educação básica. No seu artigo 35, a LDB estabelece as finalidades dessa fase de ensino:

I - a consolidação e o aprofundamento dos conhecimentos adquiridos no ensino fundamental, possibilitando o prosseguimento de estudos;

II - a preparação básica para o trabalho e a cidadania do educando, para continuar aprendendo, de modo a ser capaz de se adaptar com flexibilidade a novas condiçôes de ocupação ou aperfeiçoamento posteriores;

III - o aprimoramento do educando como pessoa humana, incluindo a formação ética e o desenvolvimento da autonomia intelectual e do pensamento crítico;

IV - a compreensão dos fundamentos científico-tecnológicos dos processos produtivos, relacionando a teoria com a prática, no ensino de cada disciplina.

Tendo como ponto de partida a idéia de uma formação integral do ser humano, os Parâmetros Curriculares Nacionais do Ensino Médio oferecem algumas pistas para o desenvolvimento de algumas habilidades específicas para o aluno de Filosofia, indo ao encontro da proposta desse nível de ensino, cuja referência pauta-se em três dimensões de formação: estética, ética e política.

$\mathrm{Na}$ dimensão estética da formação filosófica, o educando se confronta com situações que permitirão refletir criticamente sobre a necessária abertu- 
ra para a diversidade, a novidade e a criatividade. A cidadania participativa que se quer ver realizada exige pessoas com sensibilidade para questôes relacionadas ao afeto e respeito às diferenças. É preciso que o educando compreenda a própria vida como uma criação estética, em que nossas escolhas vão condicionado o caminho da vida, nos âmbitos individual e coletivo.

Para a dimensão ética, o jovem deve saber que viver é conviver, e que a vida em sociedade só tem sentido razoável se o fim a ser buscado forem a felicidade e a justeza nas ações. Para que isso aconteça, valores como respeito universal, solidariedade e liberdade devem ser problematizados constantemente de modo a confrontá-los com valores que desfiguram a face humana da sociedade, como a desonestidade, a violência e o individualismo.

Do ponto de vista político, a formação, para a vida em uma sociedade democrática, é o elo final dessa proposta de formação filosófica, posto que estética, ética e política não podem ser pensadas separadamente dentro desse projeto, mas uma tendo relação com a outra. A participação democrática do cidadão é o parâmetro para saber se se vive realmente numa democracia, ou se se utiliza essa nomenclatura sem o seu significado mais real, que é o poder do povo.

A partir dessas três dimensões, pode-se tratar das competências e habilidades propostas pelos PCNs referentes ao conhecimento de Filosofia. São enumeradas seis habilidades. A primeira habilidade a ser desenvolvida é a leitura de textos filosóficos de modo significativo. A preocupação não será apenas de apresentar esses textos de forma enciclopédica, ou o seu conteúdo, mas saber lidar com a linguagem desses textos, ser capaz de problematizá-lo, apropriando reflexivamente seu conteúdo. Do educando se espera a capacidade de análise, interpretação e crítica. Não se trata de uma formação profissional de filósofos, mas fazer com que os alunos gostem de filosofar.

Sendo evidente que o filosofar não se produz no vácuo, mas se desenvolve a partir de conteúdos concretos, vale dizer, sobre textos e discursos concretos, uma primeira escolha se impõe: não é possível pretender que o aluno construa uma competência de leitura filosófica sem que ele se familiarize, sem que ele se aproprie de um quadro referencial a partir dos conceitos, temas, problemas e métodos conforme elaborados a partir da própria tradição filosófica. (Brasil, 1999, p. 335)

Para tratar da segunda habilidade, toma-se como referência o filósofo francês Gilles-Gaston Granger, que em sua obra Por um conhecimento 
filosófico (1989) problematiza como as ciências constroem seus objetos de conhecimento e como a Filosofia também o faz. Para Granger, as ciências modernas se caracterizam por conhecer "parcelas" da realidade. Seu objeto é constituído por partes do real, são delimitações construídas por diferentes ramos de interesse que têm sua origem na ruptura que o empirismo faz no século XVII entre Filosofia e Ciência. A Filosofia, nessa separação, perde o status de ciência, mas continua pensando o todo, isto é, seu modo de conhecer não se define por um objeto específico, mas por um método específico que vai além de qualquer delimitação empírica.

Assim, compreende-se a importância da segunda habilidade, sugerida pelos PCNs, que orienta para a leitura de modo filosófico, textos de diferentes estruturas e registros.

A competência de leitura filosófica de outros discursos significa, por certo, a capacidade de problematizar e refletir a partir das estruturas e registros específicos desses discursos, isto é, lê-los com um olhar crítico. Isto pode ser traduzido também, mas não necessária ou unicamente, no exercício do reconhecimento de orientações filosóficas, refletidas ou não, originais ou não, que, eventualmente, possam habitar neles. De qualquer modo, o desenvolvimento dessa competência supõe a capacidade de articular referências culturais em geral e, mais especificamente, a capacidade de articular diferentes referências filosóficas e diferentes discursos. Uma prática, portanto, comprometida com o pressuposto de uma leitura transdisciplinar do mundo, a qual deve poder ser fomentada pela escolar na medida em que os diversos conhecimentos disponíveis se interligam numa rede. (Brasil, 1999, p. 339)

Articular conhecimentos filosóficos e diferentes conteúdos e modos discursivos nas ciências naturais e humanas, nas artes e em outras produções culturais é a terceira habilidade. Aqui a Filosofia irá problematizar o porquê e as conseqüências da fragmentação das ciências, o nascimento da Modernidade, pensar uma visão de conjunto que possa integrar os elementos culturais, e o modo de conhecer das Ciências Humanas, Naturais e Artes.

Considerando a transdisciplinaridade a partir do ponto de vista de seus próprios conteúdos disciplinares, a Filosofia pode, por exemplo, levar o estudante à apropriação reflexiva de conceitos, modos discursivos e problemas das Ciências Naturais (questão de método, estruturas discursivas 
lógico-matemáticas, e enunciação empírico-analítica etc.), das Ciências Humanas (o a priori lingüístico-cultural, estruturas discursivas críticas, a enunciação histórico-hermenêutica etc.) e das Artes (o fazer artístico, estruturas discursivas poéticas, a enunciação estético-expressiva etc.). (Brasil, 1999, p. 342)

$\mathrm{Na}$ quarta habilidade, objetivam-se contextualizar conhecimentos filosóficos, tanto no plano de sua origem específica quanto em outros planos, como o pessoal-biográfico, o contexto sociopolítico, histórico e cultural, além do horizonte da sociedade científica. Trata-se de saber articular a problematização de cada tema filosófico sem desligá-lo do contexto histórico em que foi pensado e, também, se preocupar em saber o que ele ainda tem a dizer à sociedade contemporânea.

A elaboração, por escrito, das reflexões realizadas durante as aulas, é a preocupação da quinta habilidade. Seria insuficiente um processo pedagógico que valorizasse a leitura crítica, o desenvolvimento da oralidade por meio da organização de argumentos, mas não levasse em consideração a produção escrita. Vive-se na civilização da escrita, é por meio dela que se abstrai, que se vivencia a experiência simbólica de elaboração de mundo interior. Com a escrita, combate-se o espontaneísmo de uma leitura sem compromissos com a razão e a verdade.

O debate, como sexta habilidade, procura valorizar o desenvolvimento de posturas dialógicas dos educandos, de modo que aprendam a defender suas idéias, mas também a respeitar quem pensa diferente. E mais, que saibam mudar de opinião perante argumentos mais razoáveis que os seus. Vale lembrar que a Filosofia nasce como fruto do debate na praça pública, e as obras mais conhecidas da Filosofia nascente foram escritas em forma de diálogo.

Na proposta de reforma do ensino médio do Cepae, as disciplinas passam a ter duas categorias: as do Núcleo Básico, cursadas por todos os alunos, seguindo a "base nacional comum"; e as disciplinas acessórias, que integram a "parte flexível" do currículo, o qual passa a ser construído pelo aluno.

No ensino médio, a Filosofia se insere no conjunto de mudanças propostas, ampliando o espaço da disciplina na grade curricular. Como disciplina do Núcleo Básico, é obrigatória aos alunos da 2a série. Nessa série são desenvolvidos eixos temáticos que procuram desenvolver as habilidades propostas pelo PCN de Filosofia, de tal modo que os temas se integram com a história da Filosofia. E como disciplina acessória na parte 
flexível do currículo, a Filosofia é trabalhada interdisciplinarmente com Português, História ou Geografia.

\section{Conclusão}

O ensino de Filosofia deve ter como princípio norteador o pensamento de que ensinar não é transmitir informações, mas ajudar os alunos a pensar, a discutir, a organizar argumentos. Nas palavras de Coelho (2001, p. 46), ensinar Filosofia “[...] é pensar alto e, assim fazendo, convidar os alunos para o exercício vivo do pensamento, da dúvida, da crítica, da contestação".

Tanto no ensino fundamental como no médio, o professor, na sua atividade docente, deve provocar uma permanente atitude de diálogo dos alunos com a cultura, independentemente do recurso utilizado, seja um texto, um filme, uma obra de arte. O diálogo com a cultura não é algo que se acrescenta à prática filosófica, mas o que a caracteriza por dentro. O professor deve pensar ser possível aos alunos a construção de um pensamento crítico, o qual é conquistado na medida em que o educando confronta suas idéias com as idéias dos seus colegas. O mais importante diálogo deve ser mantido com a cultura.

O projeto de ensino de Filosofia do Cepae se fundamenta nessa reflexão e nasce não como um apêndice que se acrescenta ao conjunto de disciplinas já oferecidas, mas a partir do projeto de escola pensado pelo Cepae. É um projeto que nasce dentro dessa instituição, pensando-a e contribuindo na sua função, que é refletir, pesquisar e fortalecer novas práticas de ensino na educação básica.

\section{REFERÊNCIAS}

ARANHA, M. L. A. A filosofia no ensino médio: relato de uma experiência. In: GALLO, Ślvio; KOHAN, Walter (Orgs.). Filosofia no ensino médio. 2. ed. Petrópolis: Vozes, 2000. p. 112-128.

BRASIL. Ministério da Educação. Secretaria de Educação Média e Tecnológica. Parâmetros Curriculares Nacionais: ensino médio. Brasília, DF: MEC, 1999.

CADERNOS SEAF, Rio de Janeiro: Sociedade de Estudos e Atividades Filosóficas, v. 1, n. 1, p. 3, 1978. 
CAFÉ, M. H. B. As experiências de Filosofia no $2^{\circ}$ grau. Goiânia, 1983. Mimeografado.

CHAUI, M. Convite à filosofia. 13. ed. São Paulo: Ática, 2003.

COÊLHO, I. Filosofia e educação. In: PEIXOTO, A. J. (Org.). Filosofia, educação e cidadania. Campinas, SP: Alínea, 2001. p. 19-70.

FREIRE, P. Extensão ou comunicação? 10. ed. Rio de Janeiro: Paz e Terra, 1992.

GRANGER, G.-G. Por um conhecimento filosófico. Campinas, SP: Papirus, 1989.

HORN, G. B. A presença da filosofia no currículo de ensino médio brasileiro: uma perspectiva histórica. In: GALLO, Sílvio: KOHAN, Walter (Orgs.). Filosofia no ensino médio. 2. ed. Petrópolis: Vozes, 2000. p. 1733.

MATOS, O. Filosofia, a polifonia da razão: filosofia e educação. São Paulo: Scipione, 1997.

PLATÃO. A República. 3. ed. Belém: EDUFPA, 2000.

SILVESTRE, R. J. T. O afastamento e o retorno da filosofia ao segundo grau pós-64. Mimeografado.

VYGOTSKY, L. Pensamento e linguagem. São Paulo: Martins Fontes, 1994.

Recebido em: 15 jun. 2005. Aceito em: 14 set. 2005. 